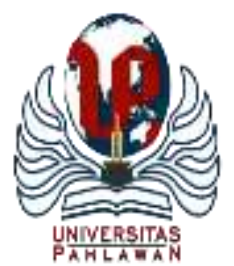

\title{
JURNALBASICEDU
}

Volume 5 Nomor 5 Tahun 2021 Halaman 3579 - 3585

Research \&Learningin Elementary Education

https://jbasic.org/index.php/basicedu

\section{Semangat Kebangsaan Berbasis Peristiwa Sejarah Lokal untuk Membangun Kesadaran Sejarah di Sekolah Dasar}

\author{
Muhammad Saleh \\ Pendidikan Guru Sekolah Dasar, Universitas Lambung Mangkurat, Indonesia \\ E-mail: msaleh@ulm.ac.id
}

\begin{abstract}
Abstrak
Artikel ini bertujuan mendeskripsikan bagaimana melihat relevansi peristiwa sejarah lokal sehingga memunculkan semangat kebangsaan. Dengan demikian, melalui semangat kebangsaan, peserta didik mampu memaknai kesadaran sejarah di jenjang Sekolah Dasar. Penelitian ini menggunakan pendekatan historis dalam menganalisis peristiwa sejarah lokal. Pendekatan historis ini untuk mengetahui peristiwa yang terjadi dalam suatu situasi sosial merupakan kajian utama penelitian kualitatif. Analisis data dilakukan dengan model interaktif Miles dan Hubermen. Hasil penelitian mendeskripsikan peristiwa sejarah lokal ideal untuk dimunculkan sebagai bahan ajar pada tema 5 "Pahlawanku" kelas IV. Di Banjarmasin, peristiwa yang dimaksud adalah peristiwa 9 November 1945 di Banua Anyar. Peristiwa 9 November 1945 di Banjarmasin merupakan serangan pemuda yang terkoordinasi oleh pemuda Banjarmasin dan sekitarnya. Berdasarkan peristiwa yang terjadi, terdapat semangat kebangsaan yang mengandung empat nilai, yaitu; rasa kesetiakawanan sosial, rela berkorban, jiwa patriotisme, dan pantang menyerah. Peristiwa 9 November 1945 ini memiliki peran yang penting bagi anak bangsa Indonesia terutama warga masyarakat Banjar. Mengedepankan sejarah lokal dalam pembelajaran diharapkan mampu memberikan pemahaman sejarah bagi peserta didik, bahwa semangat kebangsaan didapatkan dengan perjuangan.
\end{abstract}

Kata Kunci: Sejarah Lokal, Kesadaran Sejarah, dan Semangat Kebangsaan.

\begin{abstract}
This article aims to describe how to see the relevance of local historical events to raise the spirit of nationalism. Thus, through the spirit of nationalism, students can interpret historical awareness at the elementary school level. This study uses a historical approach in analyzing local historical events. This historical approach to finding out events in a social situation is the main study of qualitative research. Data analysis was carried out using the interactive model of Miles and Huberman. The study results describe the ideal Local Historical Events to be raised as teaching materials on the 5th theme, "My Heroes" class IV. In Banjarmasin, the incident referred to is November 9, 1945, in Banua Anyar. On November 9, 1945, the incident in Banjarmasin was a youth attack coordinated by the youth of Banjarmasin and its surroundings. Based on the events that occurred, there is a national spirit that contains four values, namely, a sense of social solidarity, self-sacrifice, the spirit of patriotism, and never give up. The events of November 9, 1945, have an important role for the children of the Indonesian nation, especially the people of Banjar. Prioritizing Local History in learning is expected to provide historical understanding for students that the spirit of nationality is obtained through struggle.
\end{abstract}

Keywords:Local History, Historical Awareness, and National Spriti.

Copyright (c) 2021 Muhammad Saleh

$\triangle$ Corresponding author :

Email : msaleh@ulm.ac.id

DOI : $\quad$ https://doi.org/10.31004/basicedu.v5i5.1306

ISSN 2580-3735 (Media Cetak)

ISSN 2580-1147 (Media Online)

Jurnal Basicedu Vol 5 No 5 Tahun 2021

p-ISSN 2580-3735 e-ISSN 2580-1147 


\section{PENDAHULUAN}

Pemaknaan sederhana terkait definisi pendidikan diungkapkan sebagai usaha membina sikap dan perilaku berlandaskan nilai-nilai di masyarakat (Salmon, 2019). Pendidikan dimaknai sebagai fenomena yang fundamental, hal ini dimaksudkan pada sifat kontruktif manusia (Hussin, 2018; Toshboyev et al., 2020). Pendidikan dilakukan manusia dalam beraktivitas kehidupan sehari-hari baik formal, non-formal maupun informal. Pendidikan tersebut dilakukan manusia dalam rangka memperbaiki dan meningkatkan taraf hidupnya. Pendidikan ditujukan untuk satu pencapaian agar manusia menjadi cerdas secara pengetahuan, sikap dan keterampilan (Mutiani, Supriatna, et al., 2021).

Implementasi jalur pendidikan formal dilalui dengan tiga jenjang, yaitu; dasar, menengah pertama, dan menengah atas. Ketiganya memiliki keterkaitan dimana mata pelajaran diajarkan berdasarkan kedalaman materi yang berbeda ditiap jenjangnya (Afifah, 2015). Secara khusus, pendidikan dasar diselenggarakan dengan tujuan buat meningkatkan perilaku serta keahlian dan membagikan pengetahuan serta keahlian dasar yang dibutuhkan buat hidup di dalam warga dan mempersiapkan partisipan didik yang penuhi persyaratan buat menjajaki pendidikan menengah. Adapun tujuan operasional dimaksudkan untuk membekali keahlian dasar membaca, menulis serta berhitung, pengetahuan serta keahlian dasar yang berguna untuk peserta didik cocok dengan tingkatan perkembangannya, dan mempersiapkan mereka buat menjajaki SMP (Pamuk et al., 2015; Polly \& Brantley-Dias, 2009).

Terkait dengan kemampuan dan keterampilan dasar yang bermanfaat bagi peserta didik memiliki dimensi yang kompleks. Perihal ini meliputi; keterampilan intelektual, sosial, moral, spiritual, dan personal (Mutiani, Sapriya, et al., 2021). Keseluruhan dimensi dapat diraih dengan menelaah peristiwa yang terjadi di sekitar peserta didik. Satu diantara peristiwa yang dimaksud adalah peristiwa sejarah lokal. Sejarah lokal berkiblat pada kajian sejarah dari unit analisis sosio-geografis terkecil, misalnya; desa, kecamatan, ataupun kabupaten (Hardiana, 2017). Sejarah lokal dimaksud selaku sesuatu peristiwa masa kemudian dari kelompok warga tertentu dari letak geografis tertentu, tercantum sesuatu kejadian dalam posisi yang kecil baik desa ataupun tempat tertentu ataupun daerah administratif semacam kota serta kabupaten.

Pentingnya sejarah lokal merujuk pada tujuan bagaimana guru mampu membangun kesadaran sejarah (historical awareness) di lingkup yang konkret (Mutiani et al., 2020). Sebagaimana disampaikan dalam penelitian Siska Yulia yang dilakukan pada tahun 2018, mendeskripsikan hubungan yang positif dan signifikan antara sikap, minat, dan motivasi dengan pengetahuan sejarah lokal peserta didik. Walaupun penelitian tersebut memberikan asumsi dalam paradigma positivisme, tetapi peneliti menguraikan bahwa sejarah lokal yang disajikan pada pembelajaran mampu meningkatkan rasa ingin tahu peserta didik (Siska, 2018). Tentunya hal ini relevan dengan konsepsi kesadaran sejarah.

Kesadaran sejarah mampu membangun wawasan historis serta pandangan sejarah yang menampilkan kontuinuitas menurut segala sesuatu (Aprilia \& Sukirno, 2019). Selanjutnya, disampaikan pula bahwa kesadaran sejarah mampu membantu peserta didik memaknai konsepsi dari pentingnya semangat kebangsaan dalam kehidupan bernegara (Susanti et al., 2020). Berdasarkan hal tersebut, tentunya kita sepatutnya memberikan perhatian bahwa kesadaran sejarah tidak hanya disalurkan dalam praktik pendidikan menengah atas, tetapi sedari awal di jenjang pendidikan dasar. Perihal ini mampu diakomodir melalui muatan materi IPS di Sekolah Dasar pada Kurikulum 2013 (Jumriani et al., 2021).

Materi IPS di sekolah dasar dimaksudkan untuk membentuk sikap rasional dan bertanggung jawab terhadap masalah yang timbul akibat interaksi antara manusia dan lingkungannya. Dalam konteks pengajaran IPS di sekolah dasar tidak bersifat pengetahuan. Namun, difokuskan pada kebermaknaan teori ilmu sosial, yang praktis yang berguna bagi peserta didik saat ini maupun masa akan datang (Jumriani et al., 2021). Demikian, pembelajaran IPS di sekolah dasar yang tersaji secara tematik dan integratif harus dimulai dari lingkungan keluarga peserta didik itu sendiri, lingkungan sekolah dan lingkungan sosial dengan 
membandingkan diantara sesamanya (Huda, 2016; Mutiani, et al., 2021). Hal ini perlu ditekankan untuk memperjelas kebutuhan dasar bersama, serta respek yang mengiringinya, yaitu fakta adanya keanekaragaman (Mutakin, 2004). Artikel ini bertujuan mendeskripsikan bagaimana melihat relevansi peristiwa sejarah lokal sehingga memunculkan semangat kebangsaan. Dengan demikian, melalui semangat kebangsaan, peserta didik mampu memaknai kesadaran sejarah di jenjang sekolah dasar.

\section{METODE PENELITIAN}

Penelitian ini berdasarkan pendekatan historis. Adapun yang dimaksud dengan penelitian pendekatan historis yaitu merupakan suatu pendekatan yang analisis datanya didasarkan pada peristiwa masa lampau untuk mengetahui kejadian saat ini (Sjamsuddin, 2007). Pendekatan ini menurut suatu peristiwa pada suatu waktu, kemudian diksplanasi (dikupas) untuk memahami kejadian yang ada pada saat itu guna menerapkan pada kejadian saat ini (Marihandono, 2015). Pendekatan penelitian historis ini untuk mengetahui peristiwa yang terjadi dalam suatu situasi sosial merupakan kajian utama penelitian kualitatif (Neuman, 2015). Penentuan sejarah lokal yang analisis adalah peristiwa penelitian 9 November 1945 di Banua Anyar, Banjarmasin-Kalimantan Selatan. Sumber data didapat dari tiga tahapan, yaitu; observasi, wawancara medalam, dan dokumentasi. Demikian, jenis sumber data dibagi dua, antara lain; 1) data primer berasal sumber data penelitian yang diperoleh secara langsung dari sumber aslinya yang berupa wawancara dengan sejarawan lokal, tokoh masyarakata, dan akademisi. Adapun subjek yang terlibat yaitu; Mansyur, S.Pd., M.Hum, Andy Pahwada, SE., MM, Abdul Sani, Mispansyah, Baderi; 2) data sekunder berasal dari sumber data penelitian yang diperoleh melalui media perantara atau secara tidak langsung yang berupa buku, catatan, hasil penelitian, dokumentasi, arsip daerah baik yang dipublikasikan maupun tidak. Analisis data yang digunakan adalah teknik Miles dan Huberman (Creswell, 2010; Emzir, 2010). Adapun langkahnya antara lain; 1) reduksi data dengan merangkum, memilih hal-hal yang pokok, memfokuskan pada hal-hal yang penting, pada saat wawancara dan dokumentasi; 2) penyajian data kualitatif disajikan dalam bentuk teks naratif; 3) penarikan kesimpulan berupa kegiatan interprestasi, yaitu menemukan makna dari yang telah disajikan (Afifuddin \& Saebani, 2021). Triangulasi waktu, teknik, dan sumber digunakan untuk mencek kejenuhan data. Dengan demikian, data yang digunakan dipastikan redunan (Sugiyono, 2016).

\section{HASIL DAN PEMBAHASAN}

Satu peristiwa sejarah lokal yang layak untuk dimunculkan untuk membangun kesadaran adalah peristiwa 09 November 1945. Peristiwa ini terjadi di Kalimantan Selatan, dan merupakan peristiwa yang penting bagi masyarakat Banjarmasin. Berdasarkan hasil wawancara dengan Sani Abdullah pada 11 April 2021, 9 November merupakan hari yang bersejarah bagi masyarakat Banjarmasin. Pada waktu itu banyak pejuang yang berkorban nyawa, bertumpah darah untuk melawan Belanda demi memperjuangkan Banua Bahari, Belanda telah membangun sebuah benteng yang bernama Benteng Tatas, yang waktu ini sudah menjadi Mesjid Raya Sabilal Muhtadin (Abbas, 2017). Sedangkan para pejuang Banjar bermarkas di Alam Roh yang waktu ini namanya daerah Sungai Tabuk Matan Alam Roh tambus ke Pengambangan sampai ke Pasar Lama dan Sungai Mesa, para pejuang Banua berkelompok berjuang melawan Belanda.

Tanggal, bulan dan tahun itu Badan Pemberontakan Rakyat Indonesia Kalimantan (PRIK) yang bermarkas di kelurahan Pengambangan melakukan penyerangan terhadap markas Belanda di jalan DI Panjaitan (sekarang menjadi markas besar Polda Kal-Sel). Penyerangan yang dimulai hari Jum'at sekitar pukul 16.00 WITA melibatkan 300 orang massa, dengan bambu runcing dan 20 pucuk senjata peninggalan tentara Heihol Jepang, mereka menyerbu Pantang Menyerah Waja Sampai Keputing (berusaha sampai akhir, tidak boleh menyerah, tidak mudah putus asa). Sekitar empat buah truk berat dengan serdadu Belanda bergerak cepat membrondong tembakan perlawanan rakyat Banjar, akhirnya mayat-mayat mulai 
3582 Semangat Kebangsaan Berbasis Peristiwa Sejarah Lokal untuk Membangun Kesadaran Sejarah di Sekolah Dasar-Muhammad Saleh

DOI: https://doi.org/10.31004/basicedu.v5i5.1306

bergelimpangan disana sini. Melihat kejadian ini, akhirnya beberapa tentara perlawanan rakyat Banjar mulai mundur mencari pertahanan diri untuk mengumpulkan kekuatan dan persenjataan dan kembali ke markas.

Pasca pertempuran reda, ternyata terdapat korban-korban. Antara lain M. Amin Effendi mendapat luka tembakan. Pimpinan sayap kanan Halid Tafsiar tertangkap. Selain itu ada 9 orang yang gugur sebagai kesuma bangsa yakni Badran, Badrun, Utuh, Umar, Ta'in, Juma'in, Sepa, Dulah dan Ma'rupi. Untuk memperingati semangat kepahlawanan para pemuda itu, kemudian dibangun tugu kecil (Abbas, 2017). Pada tugu kecil itu tercantum nama-nama mereka. Tugu peringatan tersebut terletak di jalan Jawa (sekarang Jalan D.I. Panjaitan) dekat tangsi polisi di mana peristiwa ini terjadi. Sedangkan tanda peringatan lainnya terdapat di Desa pengambangan Kota Banjarmasin berupa Tugu 9 November. Peristiwa 9 November 1945 di Banjarmasin merupakan serangan pemuda yang terkoordinasi oleh pemuda Banjarmasin dan sekitarnya. Hal ini menunjukkan aksi perlawanan paling awal terhadap NICA Belanda yang akan menjajah kembali Kalimantan Selatan (Syaharuddin, 2015).

Di kota Banjarmasin terdapat sebuah Tugu 9 November dan monumen pertempuran. Tugu 9 November 1945 ini terletak di depan jembatan perkembangan Banjarmasin, sedangkan Monumen di bangun di J1 DI Penjaitan di pojok Kantor Pelayana Perbendaharan Nergara (KPPN) Banjarmasin. Tugu dan Monumen ini di bangun untuk menjadi penanda suatu peristiwa yang sama bahwa pernah terjadi dulunya, namun maksud pembangunannya berbeda. Tugu 9 November 1945 di Pengambangan dibangun sebagai penanda bahwa disana merupakan markas perjuangan pada massanya, sedangkan Monumen di Jl DI Penjaitan di bangun sebagai penanda bahwa dulu pernah terjadi sebuah peristiwa pertempuran anatara pejuang melawan tentara NICA.

Sembilan nama pejuang yang tewas dalam pertempuran melawan Belanda pada Jumat 9 November 1945. Nama mereka juga diabadikan di tugu Jalan 9 November depan Jembatan Pengambangan Banjarmasin (Syaharuddin, 2020). Peristiwa 9 November menguraikan semangat kebangsaan yang tidak luntur oleh zaman untuk dikenang. Secara konseptual semangat kebangsaan dapat diartikan sebagai suatu keadaan yang menunjukkan adanya kesadaran untuk menyerahkan kesetiaan tertinggi dari setiap pribadi kepada negara dan bangsa. Semangat kebangsaan adalah satu bentuk rasa cinta tanah air. Nilai semangat kebangsaan perlu terus dibangun, sebagai generasi muda rasa kebangsaan perlu ditumbuhkan dengan terus memupuk kemampuan diri dari sisi kebangsaan. Namun, nilai semangat kebangsaan sangat penting untuk peserta didik agar bisa menghargai pehlawan dan jasa perjuangan para pahlwan yang telah gugur saat merebut kemerdakaan kita dari penjajahan Belanda/NICA serta perlawanan pemberontakan pasukan rakyat Kalimantan.

Ikatan nilai semangat kebangsaan yang selama ini tertanam dalam kehidupan masyarakat Banua Anyar dan bangsa Indonesia. Namun, nilai semangat kebangsaan terdapat beberapa nilai, diantaranya ialah rasa kesetiakawanan sosial, sikap rela berkorban, jiwa patriotisme, dan pantang menyerah (pantang mundur), yaitu sebagai berikut:

\section{Rasa Kesetiakawanan Sosial (Rasa Solidaritas Sosial)}

Kesetiakawanan sosial merupakan nilai dasar kesejahteraan sosial, suatu konsep yang ada dalam masyarakat terus digali, dikembangkan dan didayagunakan dalam mewujudkan cita-cita bangsa Indonesia untuk bernegara yaitu masyarakat sejahtera (Aziz, 2019; Hendra et al., 2018). Pada peristiwa 9 November 1945 terdapat nilai kesetiakawanan sosial, dimana para pejuang banjar tetap setia dengan pasukan BPRIK (Barisan Pemberontakan Republik Indonesia Kalimantan). Para pejuang banjar tidak akan berkhianat dari pasukan BPRIK untuk melawan para pasukan NICA (pasuakan tentara Belanda) demi mempertahankan kemerdekaaan. 
3583 Semangat Kebangsaan Berbasis Peristiwa Sejarah Lokal untuk Membangun Kesadaran Sejarah di Sekolah Dasar-Muhammad Saleh

DOI: https://doi.org/10.31004/basicedu.v5i5.1306

\section{Sikap Rela Berkorban}

Rela berkorban adalah kesediaan untuk berkorban demi kepentingan yang besar atau demi negara dan bangsa telah mengangarkan bangsa Indonesia untuk merdeka (Wahyudi \& Wibawani, 2021). Bagi bangsa yang harus didukung dengan jiwa patriotik yang tinggi. Pada peristiwa 9 November 1945 terdapat nilai rela berkorban, dimana para pejuang banjar rela berkorban demi tanah air dan bangsa. Para pejuang banjar rela mempertaruhkan nyawa demi melawan para pasukan NICA (pasukan tentara Belanda) untuk mempertahankan kemerdekaan.

\section{Jiwa Patriotisme}

Patriotisme adalah semangat cinta tanah air atau sikap seseorang yang rela mengorbankan segalagalanya untuk kejayaan dan kemakmuran tanah airnya. Patriotisme merupakan jiwa dan semangat cinta tanah air yang melengkapi eksistensi nasionalisme (Wijayanto J. \& Marzuki, 2018). Pada peristiwa 9 November 1945 terdapat nilai patrionisme, dimana para pejuang banjar semangat cinta tanah air atau sikap seseorang yang rela mengorbankan segalanya untuk kejayaan dan kemakmuran tanah airnya (Putra, 2017). Para pejuang banjar tidak akan mundur dan tetap berjuang serta tetap setia, berani dan rela berkorban untuk melawan para pasukan NICA (pasukan tentara Belanda) demi mempertahankan kemerdekaan.

\section{Pantang Menyerah}

Pantang menyerah adalah tidak mudah putus asa dalam melakukan sesuatu, selalu bersikap optimis, mudah bangkit dari keterpurukan (Sholihatin, 2019). Sikap pantang menyerah akan melahirkan pemenang (Karsono \& Suprapto, 2015). Sikap ini akan meroketkannya sampai ke puncak. Pada peristiwa 9 November 1945 terdapat nilai pantang menyerah, dimana para pejuang banjar tidak mengenal pantang menyerah dalam menghadapi para pasukan NICA (pasukan tentara Belanda). Pejuang banjar tidak akan pantang menyerah walaupun beberapa para pejuang banjar lainnya telah tewas atau bejatuhan saat berperang. Para pejuang banjar akan terus berusaha dan tidak mudah pantang menyerah melawan para penjajah demi mempertahankan kemerdekaan.

Keempat bentuk semangat kebangsaan di atas tentunya bermanfaat bagi peserta didik untuk dikembangkan di keseharian. Perihal ini berhubungan dengan karakter cinta tanah akhir sebagaimana dikembangkan oleh Kementerian Pendidikan Nasional 2010. Penanaman semangat kebangsaan melalui peristiwa sejarah lokal relevan dengan buku tema 5 "Pahlawanku" yang disajikan untuk kelas IV jenjang SD/MI. Penghargaan terhadap pahlawan tentunya tidak hanya terfokus pada pahlawan nasional semata. Tema Pahlawanku tersaji dalam tiga sub tema, yaitu; 1) perjuangan para pahlawan; 2) pahlawanku kebanggaanku; 3) sikap kepahlawanan. Ketiganya diuraikan secara kronologis sejak masa Kerajaan Hindu, Buddha, dan Islam. Pembahasan jenjang sekolah dasar sengaja tidak didesain secara mendalam dikarenakan tuntutan kompetensi yang berbeda di tiap jenjangnya. Integrasi yang dilakukan guru melalui peristiwa sejarah lokal mampu menggali peranan penting pahlawan lokal dalam peristiwa sejarah Indonesia. Keberadaan Tugu 9 November 1945 yang ada di Banua Anyar yang memiliki sarat akan nilai mulai dari bangun dan bentuk. Nilai tersebut dapat dikembangkan dalam pembelajaran tematik-integratif di sekolah dasar, khususnya pada muatan materi IPS (Mutiani, Sapriya, et al., 2021). Perihal ini relevan dengan kurikulum 2013 yang menekankan pada nilai. Nilai inilah yang nantinya diajarkan kepada pesrta didik. Nilai-nilai semangat kebangsaan yang akan diimplementasikan dalam pembelajaran. Namun penelitian ini memiliki keterbatasan dikarenakan sumber yang digunakan masih berupa sumber sekunder. Perihal ini dikarenakan minimnya ketercapaian dalam mengumpulkan arsip primer terkait peristiwa 9 November 1945. Walaupun demikian, peneliti mampu memanfaatkan beberapa penelitian terdahulu untuk mendeskripsikan persitiwa sejarah lokal sehingga relevan dengan materi ajar di jenjang sekolah dasar. 
3584 Semangat Kebangsaan Berbasis Peristiwa Sejarah Lokal untuk Membangun Kesadaran Sejarah di Sekolah Dasar-Muhammad Saleh

DOI: https://doi.org/10.31004/basicedu.v5i5.1306

\section{KESIMPULAN}

Dalam konteks pengajaran IPS di sekolah dasar tidak bersifat pengetahuan. Namun, difokuskan pada kebermaknaan teori ilmu sosial, yang praktis yang berguna bagi peserta didik saat ini maupun masa akan datang. Demikian, pembelajaran IPS di sekolah dasar yang tersaji secara tematik dan integratif harus dimulai dari lingkungan keluarga peserta didik itu sendiri, lingkungan sekolah dan lingkungan sosial. Peristiwa sejarah lokal ideal untuk dimunculkan sebagai bahan ajar pada tema 5 "Pahlawanku" kelas IV. Di Banjarmasin, peristiwa yang dimaksud adalah peristiwa 9 November 1945 di Banua Anyar. Peristiwa 9 November 1945 di Banjarmasin merupakan serangan pemuda yang terkoordinasi oleh pemuda Banjarmasin dan sekitarnya. Hal ini menunjukkan aksi perlawanan paling awal terhadap NICA Belanda yang akan menjajah kembali Kalimantan Selatan. Dalam peristiwa ini, terdapat 9 orang yang gugur sebagai kesuma bangsa yakni Badran, Badrun, Utuh, Umar, Ta'in, Juma'in, Sepa, Dulah dan Ma'rupi. Untuk memperingati semangat kepahlawanan para pemuda itu, kemudian dibangun tugu kecil. Pada tugu kecil itu tercantum nama-nama mereka. Berdasarkan peristiwa yang terjadi, terdapat semangat kebangsaan yang mengandung empat nilai, yaitu; rasa kesetiakawanan sosial, rela berkorban, jiwa patriotisme, dan pantang menyerah. Peristiwa 9 November 1945 ini memiliki peran yang penting bagi anak bangsa Indonesia terutama warga masyarakat Banjar. Mengedepankan sejarah lokal dalam pembelajaran diharapkan mampu memberikan pemahaman sejarah bagi peserta didik, bahwa semangat kebangsaan didapatkan dengan perjuangan. Peserta didik sebagai generasi penerus harus memaknai peristiwa sejarah lokal sebagai bagian dari perjuangan kemerdekaan Indonesia yang panjang.

\section{DAFTAR PUSTAKA}

Abbas, E. W. (2017). Pendidikan Sejarah, Patriotisme \& Karakter Bangsa Malaysia-Indonesia. Banjarmasin: Pendidikan Ips Ulm.

Afifah, N. (2015). Problematika Pendidikan Di Indonesia (Telaah Dari Aspek Pembelajaran). Elementary: Jurnal Ilmiah Pendidikan Dasar, 1(1), 41-47.

Afifuddin, \& Saebani, B. A. (2021). Metodologi Penelitian Kualitatif. Bandung: Pustaka Setia.

Aprilia, R., \& Sukirno, S. (2019). Pengembangan Buku Ajar Ips Berbasis Sejarah Lokal Kelas Iv Sd Kabupaten Aceh Tengah. Seuneubok Lada: Jurnal Ilmu-Ilmu Sejarah, Sosial, Budaya Dan Kependidikan, 6(1), 11-20.

Aziz, A. (2019). Pendidikan Etika Sosial Berbasis Argumentasi Quranik. Andragogi: Jurnal Pendidikan Islam Dan Manajemen Pendidikan Islam, 1(3), 466-489. Https://Doi.Org/10.36671/Andragogi.V1i3.68

Creswell, J. W. (2010). Research Design Pendekatan Kualitatif, Kuantitatif, Dan Mixed. Yogyakarta: Pustaka Pelajar.

Emzir. (2010). Analisis Data: Metodologi Penelitian Kualitatif. Jakarta: Rajawali Pers.

Hardiana, Y. (2017). Pembelajaran Sejarah Indonesia Berbasis Peristiwa-Peristiwa Lokal Di Tasikmalaya Untuk Meningkatkan Kemampuan Berpikir Kritis. Historia: Jurnal Pendidik Dan Peneliti Sejarah, 1(1), 41-46. Https://Doi.Org/10.17509/Historia.V1i1.7008

Hendra, Budijanto, \& Ruja, I. N. (2018). Penguatan Kesetiakawanan Sosial Peserta Didik Melalui Nilai Budaya Perayaan Maudu Lompoa. Jurnal Pendidikan: Teori, Penelitian, Dan Pengembangan, 3(10), 1339-1342.

Huda, T. F. (2016). Pemanfaatan Petilasan Macan Putih Sebagai Sumber Belajar Sejarah Lokal Bagi Generasi Muda. Historia: Jurnal Program Studi Pendidikan Sejarah, 4(1), 55-64.

Hussin, A. A. (2018). Education 4.0 Made Simple: Ideas For Teaching. International Journal Of Education And Literacy Studies, 6(3), 92-98. 
3585 Semangat Kebangsaan Berbasis Peristiwa Sejarah Lokal untuk Membangun Kesadaran Sejarah di Sekolah Dasar-Muhammad Saleh

DOI: https://doi.org/10.31004/basicedu.v5i5.1306

Jumriani, Syaharuddin, Hadi, N. T. F. W., Mutiani, \& Abbas, E. W. (2021). Telaah Literatur ; Komponen Kurikulum Ips Di Sekolah Dasar Pada Kurikulum 2013. Jurnal Basicedu, 5(4), 1020-2035.

Karsono, O. M. F., \& Suprapto, W. (2015). Manifestasi Sifat Gigih Pantang Menyerah Pemilik Usaha Keluarga Etnis Tionghoa Jawa Timur (Doctoral Dissertation). Surabaya: Petra Christian University.

Marihandono, D. (2015). Memanfaatkan Karya Sastra Sebagai Sumber Sejarah. In Stella Rose (Ed.), Prosiding Sastra Dan Solidaritas Bangsa. Ambon: Kantor Bahasa Maluku.

Mutakin, A. (2004). Konsep Dasar Pengorganisasian Pembelajaran Ips Di Sekolah Dasar. Bandung: Bina Siswa.

Mutiani, Abbas, E. W., Syaharuddin, \& Susanto, H. (2020). Membangun Komunitas Belajar Melalui Lesson Study Model Transcript Based Learning Analysis. Pendidikan Dan Penelitian Sejarah, 3(2), 113-122. Https://Doi.Org/Https://Doi.Org/10.17509/Historia.V3i2.23440

Mutiani, M., Supriatna, N., Abbas, E. W., Rini, T. P. W., \& Subiyakto, B. (2021). Technological, Pedagogical, Content Knowledge (Tpack): A Discursions In Learning Innovation On Social Studies. The Innovation Of Social Studies Journal, 2(2), 135-142. Https://Doi.Org/10.20527/Iis.V2i2.3073

Mutiani, Sapriya, Handy, M. R. N., Abbas, E. W., \& Jumriani. (2021). Pembinaan Etika Peserta Didik Melalui Pembelajaran Tematik - Integratif Di Sekolah Dasar. Edukatif: Jurnal Ilmu Pendidikan, 3(3), 704-709.

Neuman, W. L. (2015). Metodologi Penelitian Sosial: Pendekatan Kualitatif Dan Kuantitatif. Jakarta: Pt Indeks.

Pamuk, S., Ergun, M., Cakir, R., Yilmaz, H. B., \& Ayas, C. (2015). Exploring Relationships Among Tpack Components And Development Of The Tpack Instrument. Education And Information Technologies, 20(2), 241-263. Https://Doi.Org/10.1007/S10639-013-9278-4

Polly, D., \& Brantley-Dias, L. (2009). Tpack: Where Do We Go Now? Techtrends, 53(5). Https://Doi.Org/10.1007/S11528-009-0324-4

Putra, Y. S. (2017). Perkembangan Jiwa Nasionalisasi Dan Patriotisme Era Reformasi Di Indonesia. Jurnal Dosen Universitas Pgri Palembang.

Salmon, G. (2019). May The Fourth Be With You. Journal Of Learning For Development, 6(2), 95-115. Https://Doi.Org/10.1145/3133956.3134029

Sholihatin, N. (2019). Pengaruh Novel Api Tauhid Terhadap Sikap Pantang Menyerah Di Kalangan Santriwati Muzamzamah Darul Ulum Jombang (Doctoral Dissertation). Uin Sunan Ampel Surabaya.

Siska, Y. (2018). Korelasi Sikap, Minat, Dan Motivasi Belajar Dengan Pengetahuan Sejarah Lokal Lampung. Mimbar Sekolah Dasar, 5(1), 51-62. Https://Doi.Org/10.17509/Mimbar-Sd.V5i1.9856

Sjamsuddin, H. (2007). Metodologi Sejarah. Yogyakarta: Ombak.

Sugiyono. (2016). Memahami Penelitian Kualitatif. Bandung: Alfabeta.

Susanti, S. W. R., Wulandari, Y., \& Nahrowi, M. (2020). Pengembangan Bahan Ajar Dengan Pendekatan Kontekstual Berbasis Situs Sejarah Untuk Meningkatkan Pendidikan Karakter. Heritage: Journal Of Social Studies, 1(1), 89-109.

Syaharuddin. (2015). Transformasi Nilai-Nilai Kejuangan Masyarakat Banjar Pada Periode Revolusi Fisik (1945-1950) Di Kalimantan Selatan (Studi Etnopedagogi Dalam Pengembangan Kurikulum Pendidikan Ips). Universitas Pendidikan Indonesia.

Syaharuddin, S. (2020). Nilai-Nilai Kejuangan Masyarakat Banjar Pada Periode Revolusi Fisik (1945-1950) Sebagai Sumber Pembelajaran Ips. International Seminar Strengthening Social Studies For The Twenty First Century (Memperkuat Pendidikan Ips Menghadapi Abad 21).

Toshboyev, B. E., Amanlayev, A. X., \& Shukurova, F. K. (2020). The Impact Of Changing Paradigms In The National Mentality On The Education Of The Individual. Theoretical \& Applied Science, 84, 272-275. 
3586 Semangat Kebangsaan Berbasis Peristiwa Sejarah Lokal untuk Membangun Kesadaran Sejarah di Sekolah Dasar-Muhammad Saleh

DOI: https://doi.org/10.31004/basicedu.v5i5.1306

Https://Doi.Org/10.15863/Tas.2020.04.84.48

Wahyudi, E., \& Wibawani, S. (2021). Pembentukan Sikap Rela Berkorban Mahasiswa Melalui Mata Kuliah Patriotisme. Jurnal Pertahanan \& Bela Negara, 11(1), 15-30.

Wijayanto J., R., \& Marzuki, M. (2018). Pendidikan Bela Negara Sebagai Tonggak Peradaban Jiwa Patriotisme Generasi Muda. Jurnal Ilmiah Pendidikan Pancasila Dan Kewarganegaraan, 3(2), 186-191. Https://Doi.Org/10.17977/Um019v3i2p186-191. 